\title{
Research Paper: \\ The Effect of a Parental Education Program on the Mental Health of Parents and Behavioral Problems of Their Children With Autism Spectrum Disorder
}

\author{
Mitra Hakim Shooshtari ${ }^{1}$, Hadi Zarafshan ${ }^{2}$, Mehrdad Mohamadian ${ }^{1}$, *Jamileh Zareee $^{3}$, Isa Karimi Keisomi ${ }^{4}$, Helia \\ Hooshangi ${ }^{4}$
}

1. Mental Health Research Center, School of Medicine, Iran University of Medical Sciences, Tehran, Iran.

2. Psychiatry \& Psychology Research center, Roozbeh Hospital, Tehran University of Medical Science, Tehran, Iran.

3. Spiritual Health Research Center, School of Behavioral Sciences and Mental Health, Psychology Group, Iran University of Medical Sciences, Tehran, Iran.

4. School of Behavioral Sciences and Mental Health (Tehran Institute of Psychiatry), Iran University of Medical Sciences, Tehran, Iran.

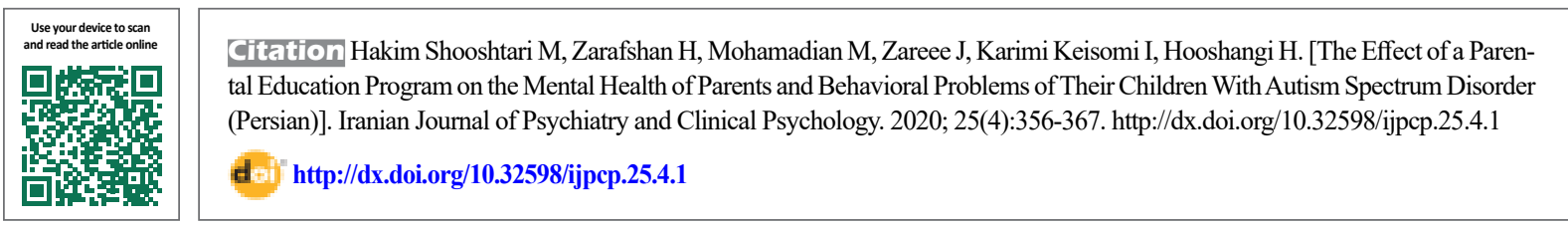

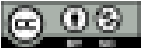

Received: 14 Sep 2018 Accepted: 21 Jul 2019 Available Online: 01 Jan 2020

Key words: Autism Spectrum Disorder, Parental education, Behavioral problems

\begin{abstract}
AB STRACT
Objectives Early interventions can play an important role in alleviating or eliminating many of the major symptoms of Autism Spectrum Disorder (ASD) and enhancing new skills. Parental education can reduce the parents' depression and stress and increase their empowerment. This study aimed to evaluate the effect of a parental education program the mental health of parents, behavioral problems of their children with ASD.

Methods A group of 30 parents of children with ASD in Tehran, Iran were selected by a convenience sampling and were randomly divided into intervention and control groups. The parents in the intervention group received psychoeducational program according to Tonge et al.'s (2006) method in 10 sessions each for 90 min in Tehran Psychiatric Institute. Data collection tools were the Family Assessment Device, the Childhood Autism Rating Scale, Billings and Mouse's Coping Strategies Scale, and 28-item General Health Questionnaire. All participants were evaluated at three stages of pretest, posttest, and 3-month follow-up.

Results The effect of parental education program on the clinical symptoms and its dimensions was significant at three measurement phases. In the 3-month follow-up duration, the results remained unchanged. There were a significant difference between the two study groups in general health, family function, coping strategies, and child behavior ( $F=4.859, P=0.023)$.

Conclusion Parental education can improve the mental health of parents and reduce the behavioral problems of their ASD children.
\end{abstract}

\section{Extended Abstract}

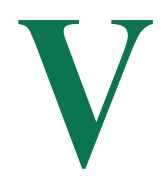

\section{Introduction}

arious studies in Iran conducted on the parents of children with Autism Spectrum Dis- order (ASD) have shown that these parents have a higher degree of stress and mental health problems compared to the parents of children with no ASD [4-6]. The stress level that these parents experience are affected by the resources that are available to them $[7,8]$. The parents participating in supportive group training experience less stress in the rela-

\section{* Corresponding Author:}

Jamileh Zareee, PhD.

Address: Spiritual Health Research Center, School of Behavioral Sciences and Mental Health, Psychology Group, Iran University of Medical Sciences, Tehran, Iran.

Tel: +98 (912) 5275507

E-mail: mitra.hakim@gmail.com 
tionship with their ASD children and feel less social isolation [12].

The study by Ahmadi et al. (2011) on the needs of parents of children with ASD in Iran showed that these parents reported their most important needs as receiving guidance and information on the cause of problematic and abnormal behaviors in children and how to deal with these behaviors. They also emphasized on the need to spend time with friends and being supported by other members of the family [13]. Tonge et al. [21] studied the effect of a 20 -week education program teaching behavioral management skills on the parents of children with ASD aged 2.5-5 years. Their results showed that the parents participating in this program had a higher improvement in mental health than the control group. The present study aimed to examine the effect a parental education program on the mental health of parents and behavioral problems of their children with ASD.

\section{Methods}

The study samples $(n=30)$ were selected from among the parents of children with ASD referred to the clinic of Tehran Psychiatric Institute. All of these children were examined by a pediatric psychiatrist before entering the study and their ASD was diagnosed based on the criteria of the Diagnostic and Statistical Manual of Mental Disorders, Fifth Edition (DSM-5). Inclusion criteria for participants were having at least one child with ASD at pre-school and school age, and not attending other courses of behavioral education for parents in the last 3 years. Before collecting data, the study purpose was explained to the subjects and written informed consent was obtained from all of them.

\section{Results}

Table 1 shows the demographic characteristics of children and their mothers. Regarding the type of study (interventional) and various problems of patients, the results were analyzed in two groups of 12 patients due to initial sample drop. The first post-test measurement was conducted one week after the intervention. General health was assessed before and after the intervention. The ANCOVA was used to analyze the effect of psychoeducational program. For one-way ANOVA, first the equality of covariance matrix was tested by Mauchly's test of sphericity. Since the significance level of the Mauchly's sphericity was greater than $0.05(\mathrm{w}=0.909, \mathrm{P}<0.05)$, the homogeneity assumption of variances was supported and ANCOVA can be used. A summary of ANOVA results is presented in Table 2. Considering that the calculated $\mathrm{F}(4.958)$ is significant $(\mathrm{P}=-$ $0.023)$, it can be said that there is a significant difference in general health, family functioning, child behavior, and coping strategies between two intervention and control groups.

Multivariate ANCOA results indicated the significant effect of psychoeducational program on the reduction of clinical symptoms. The findings showed that the $\mathrm{F}$ ratio obtained from the comparing the mean scores of clinical symptoms in the pretest and posttest phases was significant $(\mathrm{F}=321.991, \mathrm{P}<0.05)$ (Table 3). Furthermore, results of Bonferroni post-hoc test showed that psychoeducational program in the post-test and follow-up phases had a significant effect on the reduction of clinical symptoms and the results remained constant during the 3-month follow-up phase $(\mathrm{P}<0.05)$.

\section{Discussion and Conclusion}

Studies conducted in Iran show that parents of children with ASD have a higher degree of stress and mental health problems compared to the parents of normal children [4-6]. They highly need to receive information about ASD and how to deal with it and gain social support $[13,14]$. This program showed that having information about the disease can improve coping strategies, mental health, child behavior, and family functioning. By such training groups, parents can have time and space to discuss about their reactions to their children's disease, their emotions and the impact of this disease on them and their family members. The results of present study indicated the effect of parental group training in the field of ASD and its management skills on the mental health of parents. This training can provide an opportunity for the parents' participation in the groups and receiving information for dealing with their ASD children's behaviors.

\section{Ethical Considerations}

\section{Compliance with ethical guidelines}

All ethical principles were considered in this article. The participants were informed about the purpose of the research and its implementation stages; they were also assured about the confidentiality of their information; Moreover, They were allowed to leave the study whenever they wish, and if desired, the results of the research would be available to them.

\section{Funding}

This research did not receive any specific grant from funding agencies in the public, commercial, or not-forprofit sectors. 


\section{Authors contributions}

Conceptualization and Methodology: Mitra Hakim shooshtari; Editing and Review: Jamileh Zareee; Writing and Data analysis: Hadi Zarafshan, Mehrdad Mohamadian, Isa Karimi Keisomi, Hooshangi Helia.

\section{Conflicts of interest}

The authors declared no conflict of interest. 


\section{تأثير آموزش تروهى والدين بر سلامت روان والدين و كاهش مشكلات كودكان دهار اختلالات طيف

ميترا حكيم شوشترى'، هادى زرافشان"، مهرداد محمديان'، "جميله زارعى' •، عيسى كريمى كيسمى' هليا هوشنكى

ا. ا. بركز تحقيقات بهناشت روان، دانشكده يزشكى، انشكاه علوم يزشكى ايران، تهران، ايران.

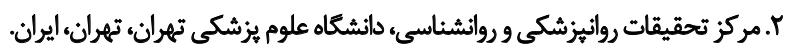

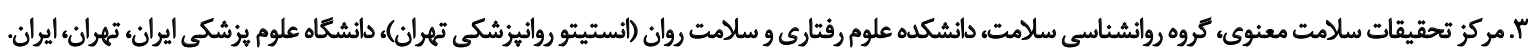

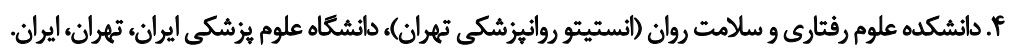

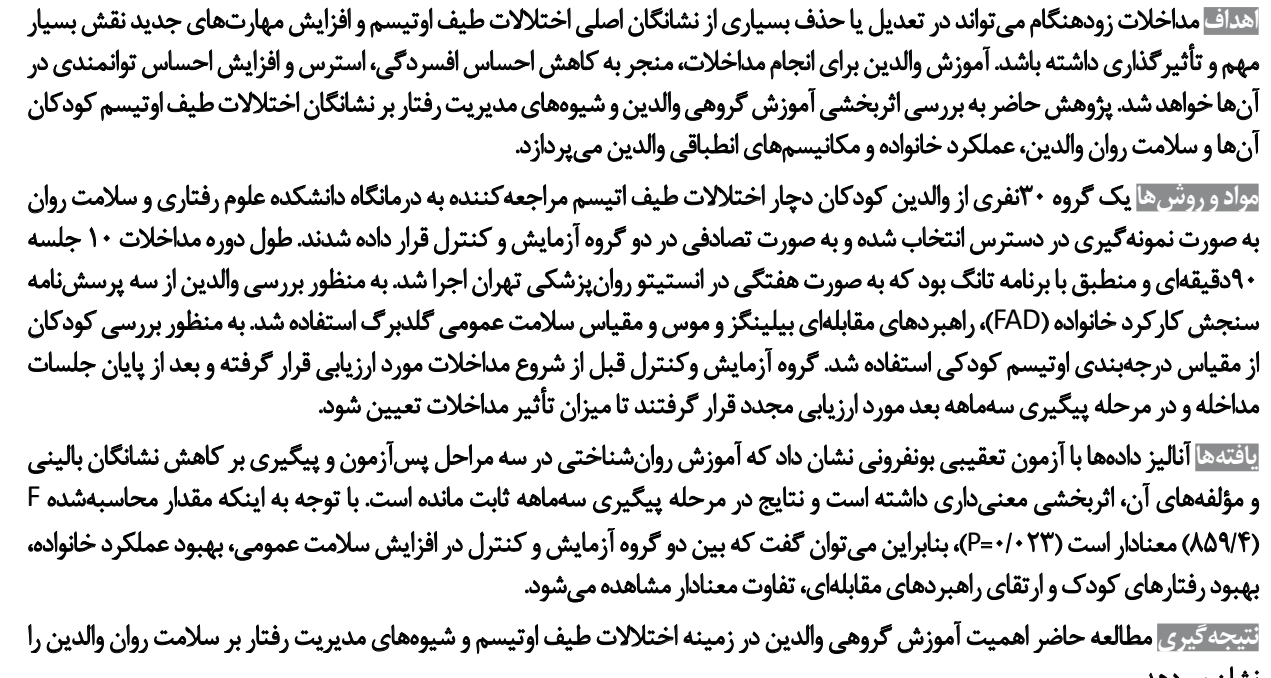

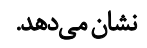

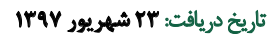

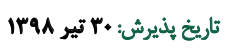

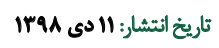

كليدواثرها:

اختلالات طيف اوتيسه، آموزش كروهى والدين،

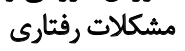

والدين در مقايسه با والدين كودكان فاقد اختلالات طيف اوتيسم

مقدمه

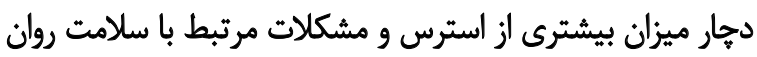

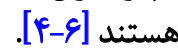

سطح استرسى كه والدين كودكان مبتلا به اختلالات طيف

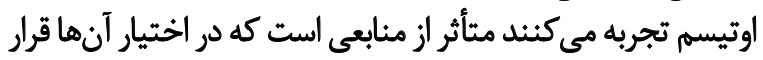

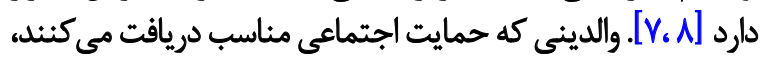

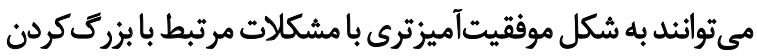

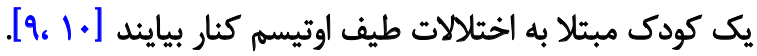

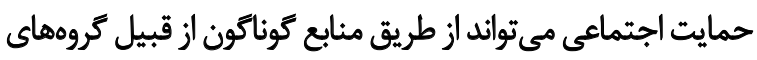

اختلالات طيف أوتيسم منجر به عوامل فشارزاى ويرٔماى از قبيل

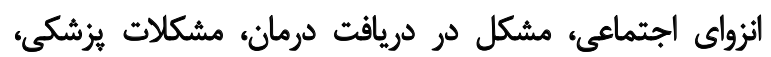

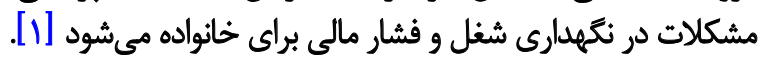

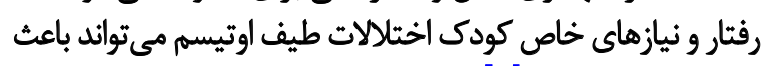

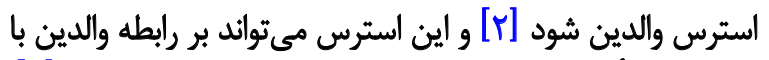

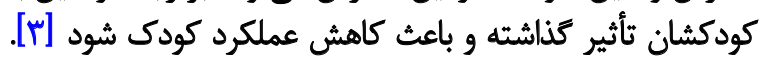

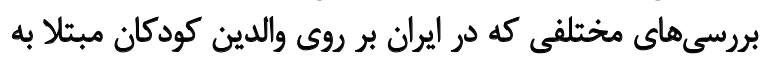

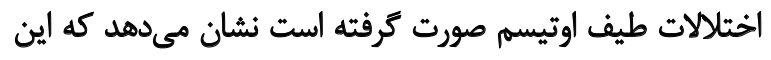


از رفتّار مربى در هحيط واقعى و بازخوردكيرى مورد آموزش قرار

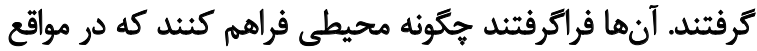

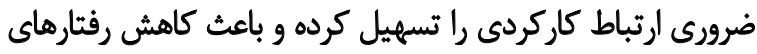

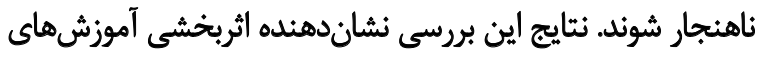
فراكرفته شده توسط والدين بود.

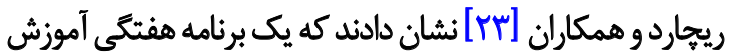

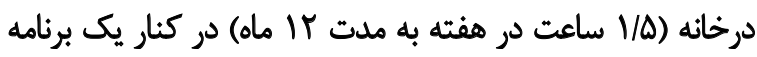

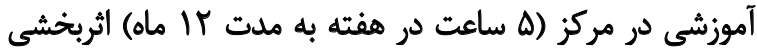

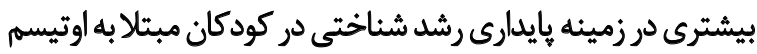

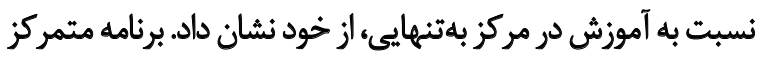

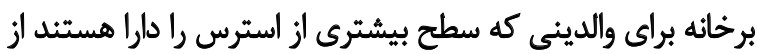
اثربخشى بيشترى برخوردار است.

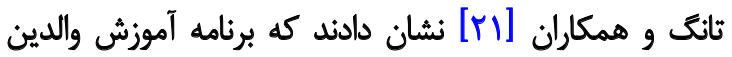

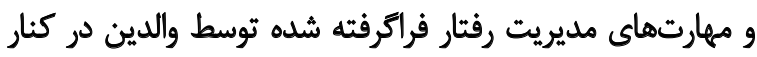

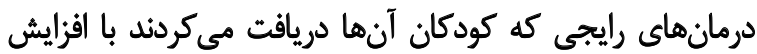

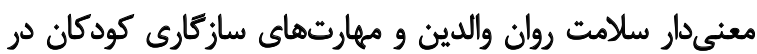
مقايسه با كروه كنترل در ارتباط بود.

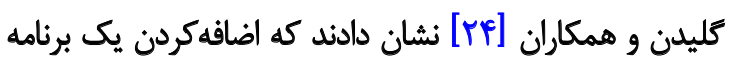

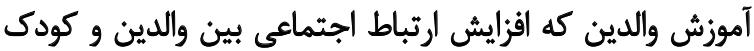

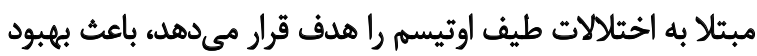

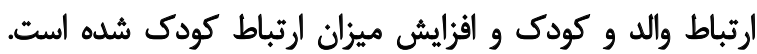

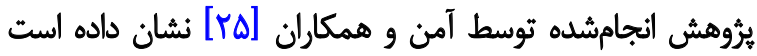

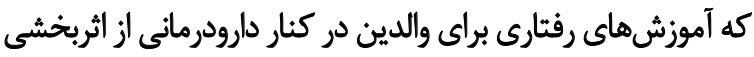

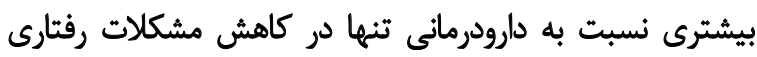
كودكان مبتلا به اختلالات طيف اوتيسم داشته است.

با توجه شواهد موجود مبنى بر نياز والدين ايرانى به دريافت

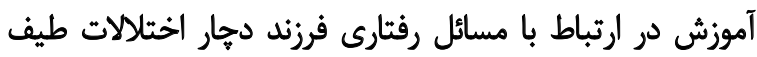

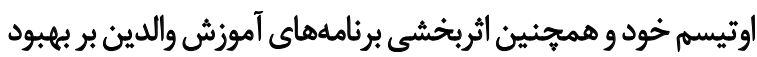

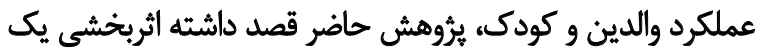

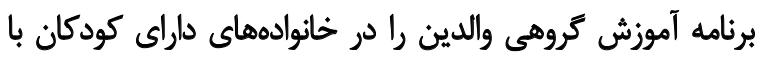

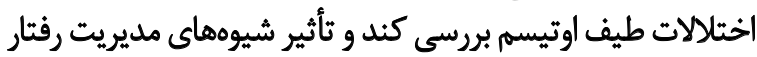

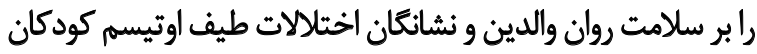

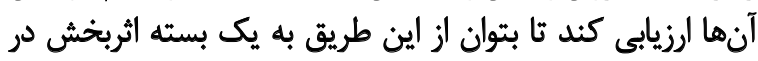

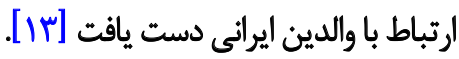

وروش

در يثروهش حاضر به منظور بررسي تأثير آموزش كروهى والدين

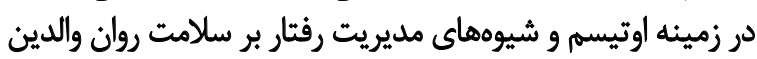

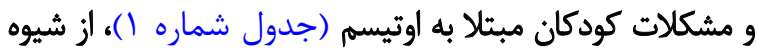

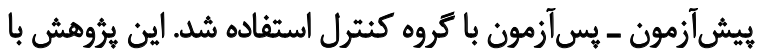

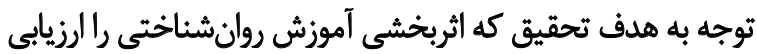

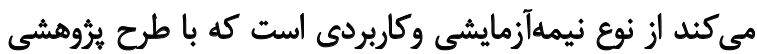

حمايتى كه توسط والدين كودكان مبتلا به ناتوانى شكل ترفيته است

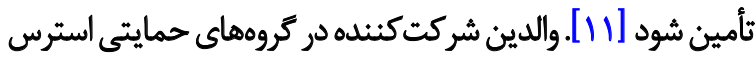

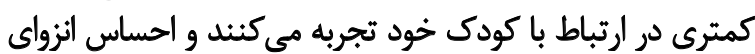

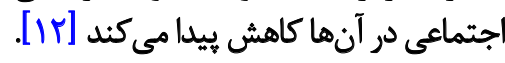

بروسى احمدى و همكاران (11 (Y) در زمينه نيازهاى والدين

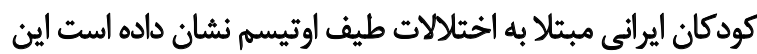

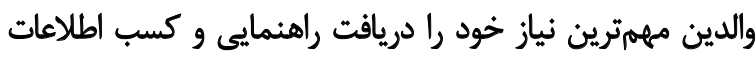

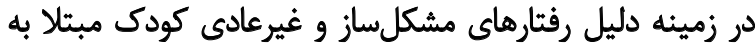

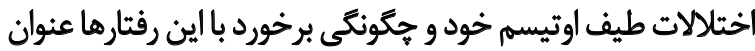

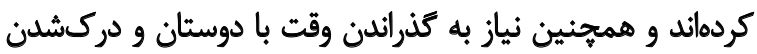

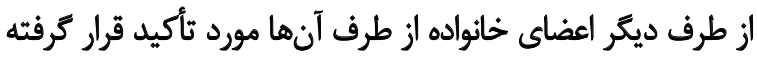

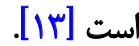

نتايج مطالعه ديكرى كه توسط صمدى و همكاران (11 + إن) درباره

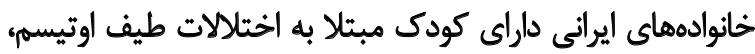

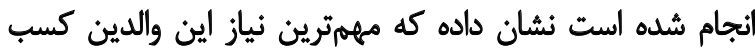

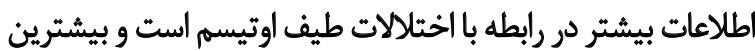

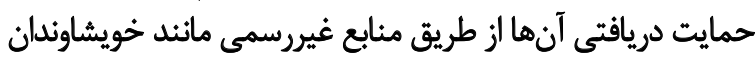

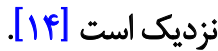

اين عقيده كه والدين كودكان مبتلا به اختلالات طيف اوتيسم بايد

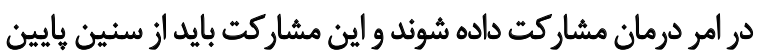

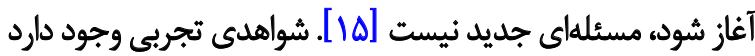

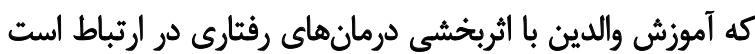

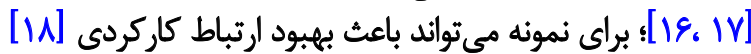

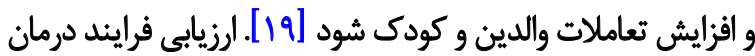

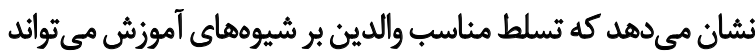

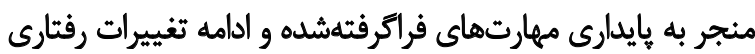
در طول زمان شود [r. [ب.

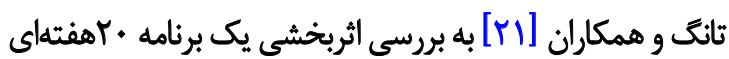

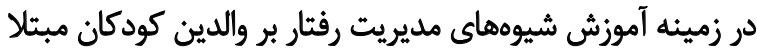

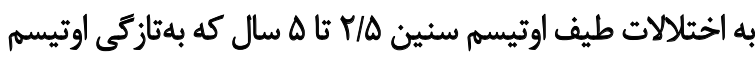

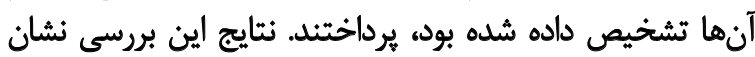

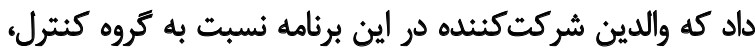

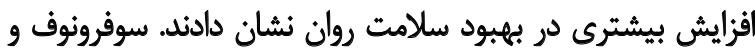

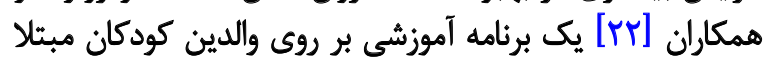

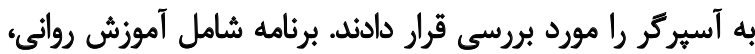

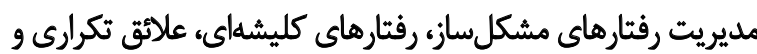

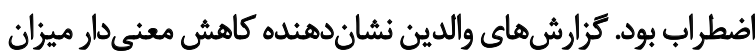

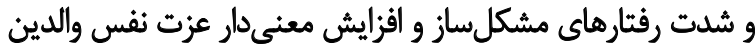

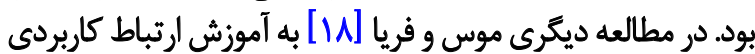

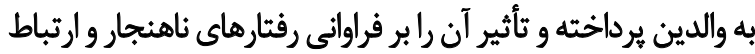

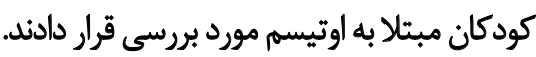
والدين براى يادكيرى •A درصد مهارتها از طريق الكوكيرى 
و بر اساس معيارهاى تشخيصى راهنماى ينجمم آمارى و تشخيصى رئي

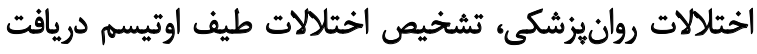

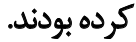

معيار ورود براى شركتكنيدكان داشتن حداقل يك كودى

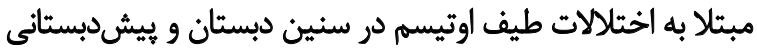

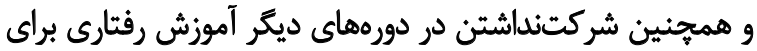

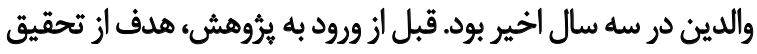

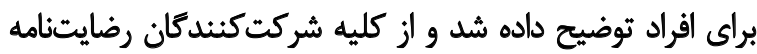
كتبى كرفته شد. حجم نمونه با استفاده از نسخه

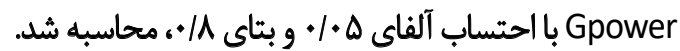

يُش آزمون - يّ آزمون با كروه كنترل و مرحله يُيكيرى انجام شد.

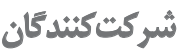
يك كروه • انفرى از والدين كودكان مبتلا به اوتيسم به صورت

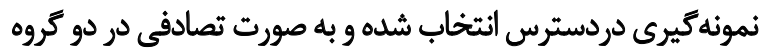

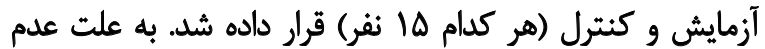

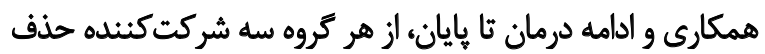

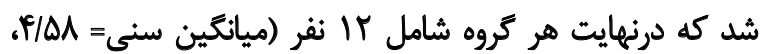

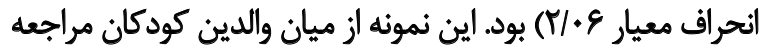

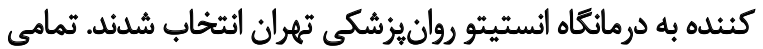

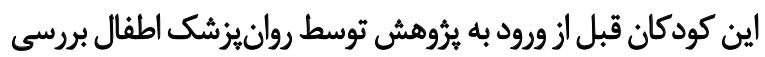

جدول ا. تأثير آموزش تروهى والدين

\begin{tabular}{|c|c|c|}
\hline جزئيات جلسات & اهداف & تعداد جلسات \\
\hline 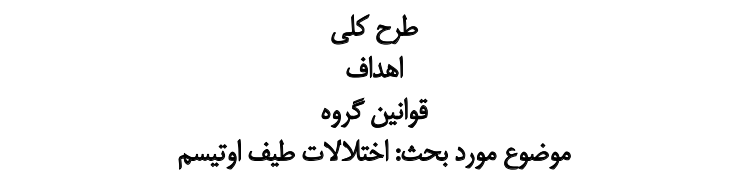 & طرح كلى و اهد|ف برنامه & جلسه اول \\
\hline أسترس به كنارآخيصن & مسائل والدين بعد ازز تشخيص & 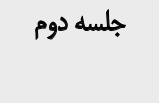 \\
\hline مديريث رفثتار جيست؟ & شناخت و مديريت رفتار مشكلساز & جلسه سوم \\
\hline خاموشئسازي رفتارى & جكونه با دست كارى ييامدها، رفتار & جلسه جهارم \\
\hline 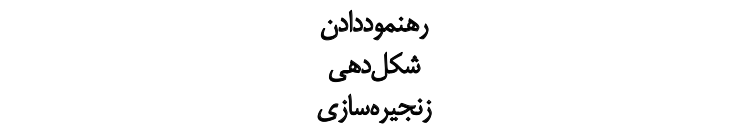 & جكونه رفتار جلديد را تقويت كنيم & جلسه ينجم \\
\hline جكونه اين مشكلات زبانى رفتار كودكان داراى كلام كلام را تحت تأثير قرار مىدهد؟ & اختلالات طيف ارتباطى در كودكان مبتلا به داراى كلام & ملسه ششمر \\
\hline 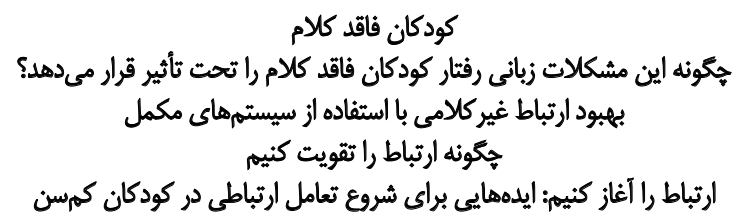 & مشكلات ارتباطي در كودكان فاقد كلام & جلسه هفتم \\
\hline 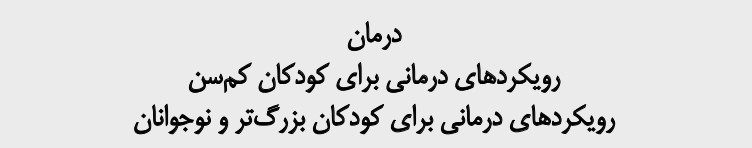 & نارسايى اجتماعى در اختلالات طيف & جلسه هشتم \\
\hline 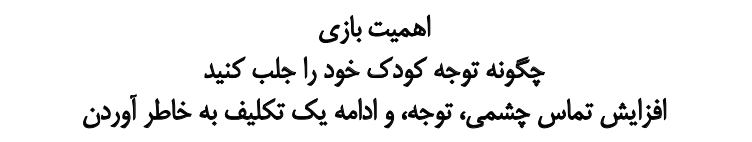 & جكونكى بازى و كار با يكديكر & جلسه نزم \\
\hline نقد و بررسى جلسات كذشته & & جلسه دهم \\
\hline
\end{tabular}




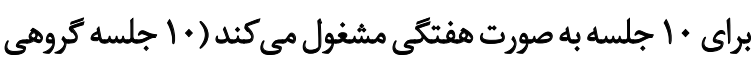

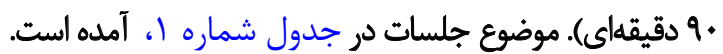

\section{مثياس سئجش كاركرد خانواده (FAD)}

اين مقياس براى سنجش كاركرد خانواده توسط إيشتاين، بالدوين

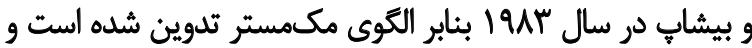

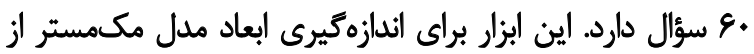

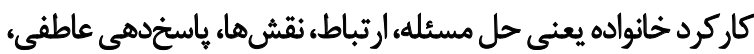

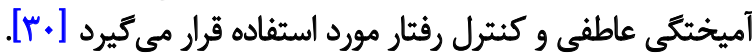

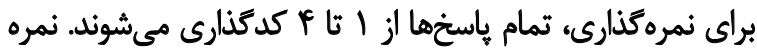
بالاتر نشاندهنده كاركرد ناسالمتر است.

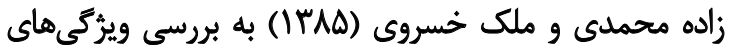

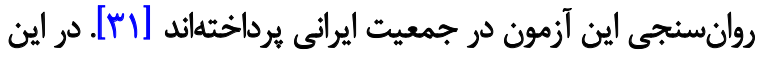

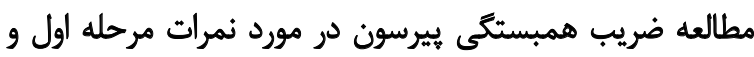

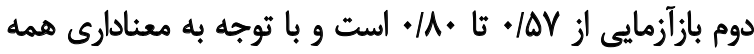

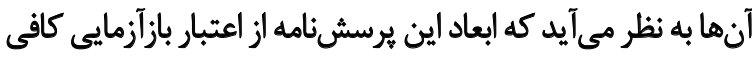

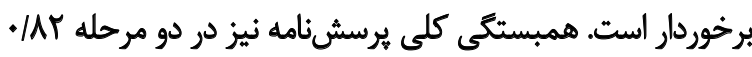

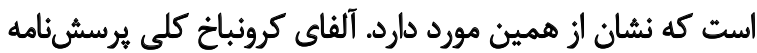

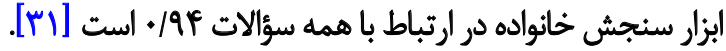

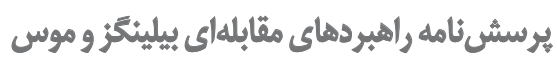

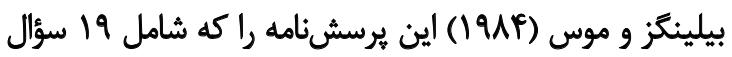

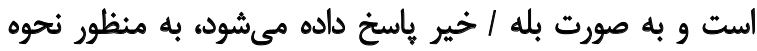

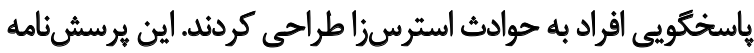

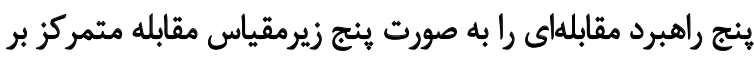

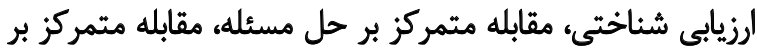

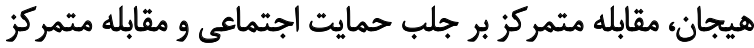

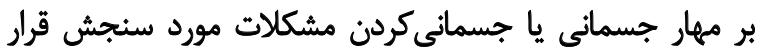

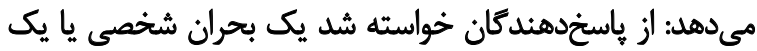

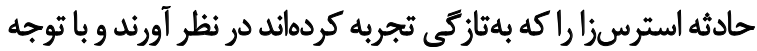

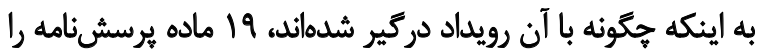

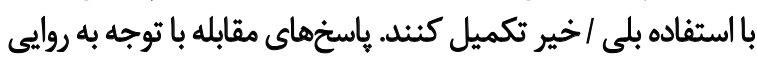

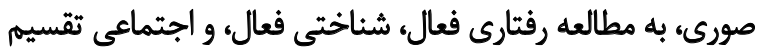

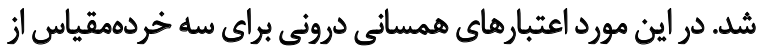

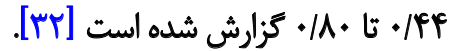

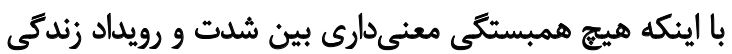

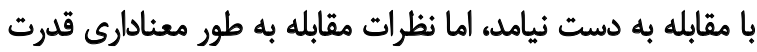

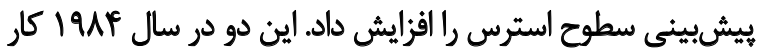

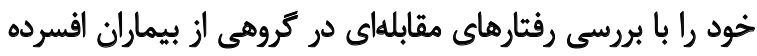

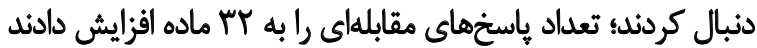

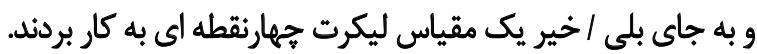

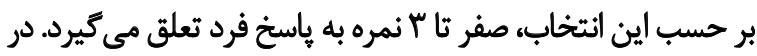

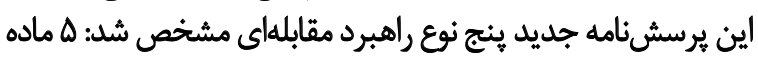

ووش إيرا

كروه آزمايش و كنترل قبل از شروع مداخله مورد ارزيابى قرار

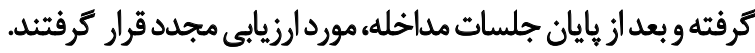

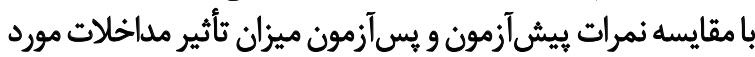

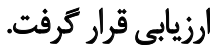

بيش آزمون يك هفته قبل از شروع مداخلات و در جلات جلسه معارفه و يس آزمون يك هفته بعد از اتمام مداخلات انجام شد.

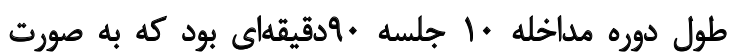

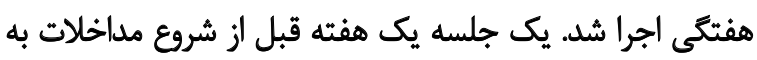

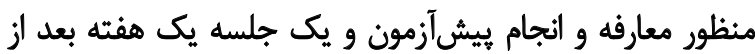

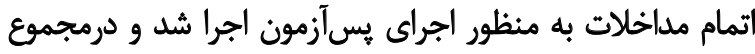

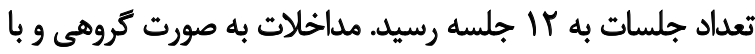

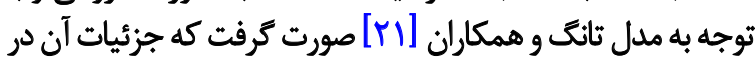

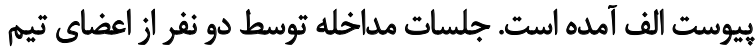
يرؤش (دكتر ميترا حكيم شوشترى و دكتر هادى زرافشان) بركزّزار

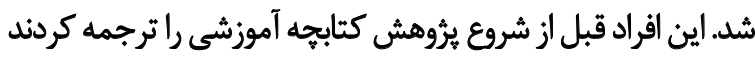

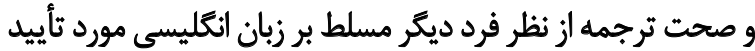

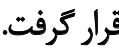

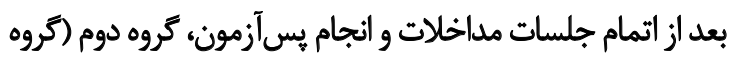

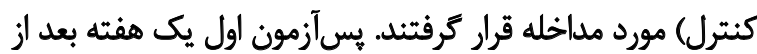

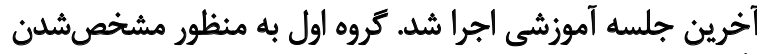

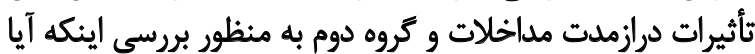

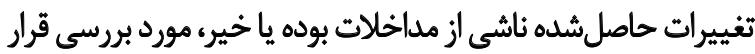

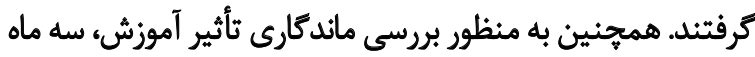

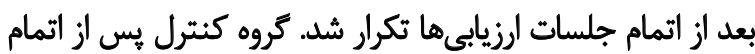

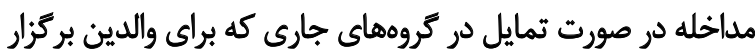

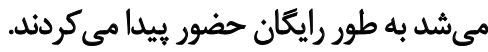

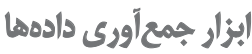

به منظور بررسى والدين سه يرسشنامه سنجش كاركرد خانواده بيلينز و (Family Assessment Devic: FAD)

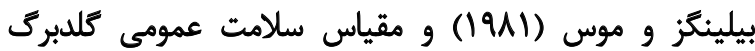

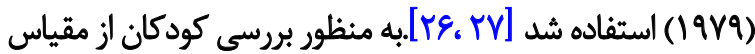

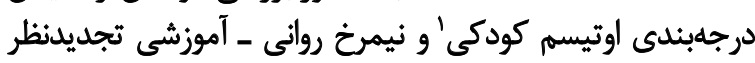

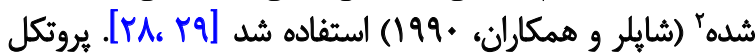
اجرا شده در طى •l جلسه به صورت زير اجران شاند:

$$
\text { طرح كلى برنامه }
$$

تقريباً سه ماه طول مي كشد تا اين برنامه تمام شود و خانوادهها را

1. Childhood Autism Rating Scale (CARS)

2. Psychoeducational Profile-Revised 
مرتبط با اختلالات طيف اوتيسم در افراد بالاتر از دو سال توسط

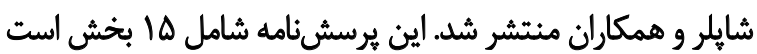

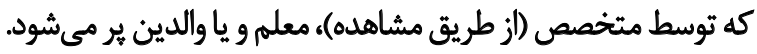

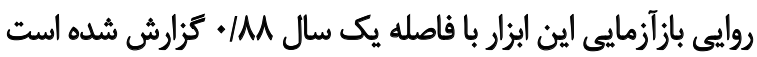

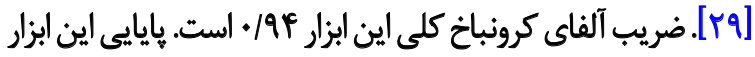

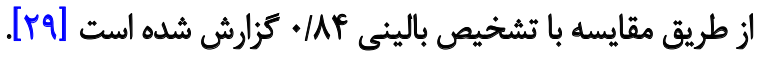

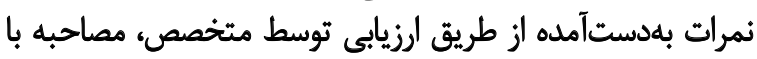

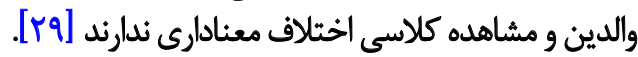

يانثنهها

جدول شماره Y خصوصيات جمعيتشناختى كودكان و مادر را ا

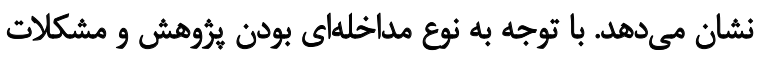

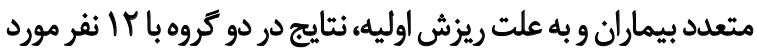

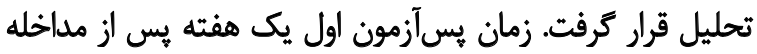

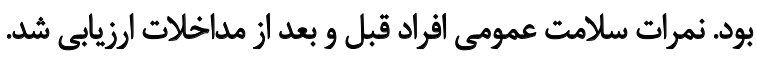

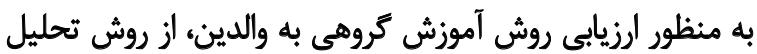
كوواريانس استفاده شد.

براى تحليل واريانس يك عاملى ابتدا يكسانى كوواريانس هاى متغير

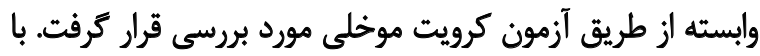

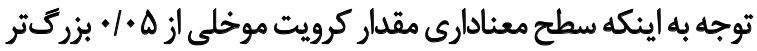

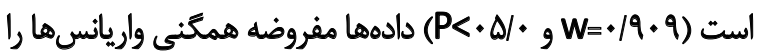

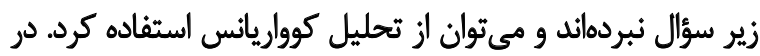

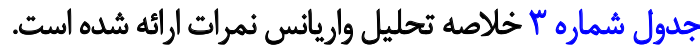

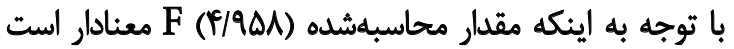

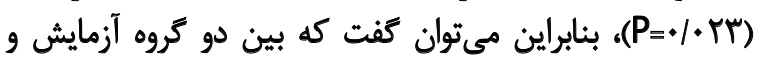

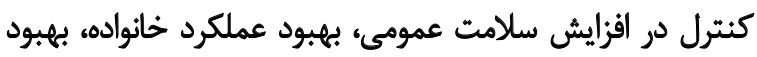

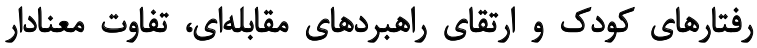

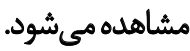

مربوط به مقابله متمركز بر ارزيابى شناختى، ب ماده مربوط به ماده مقابله

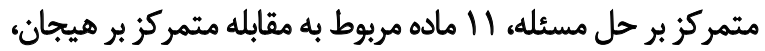

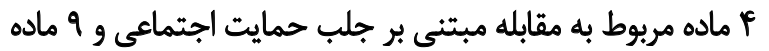

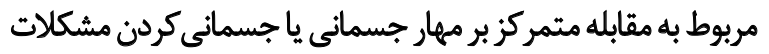

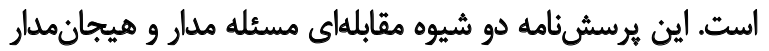

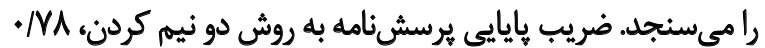

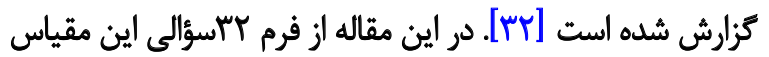
استفاده شد.

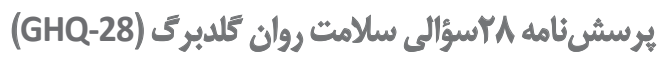

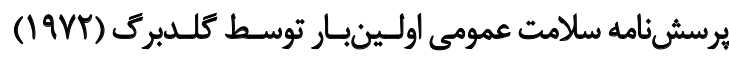

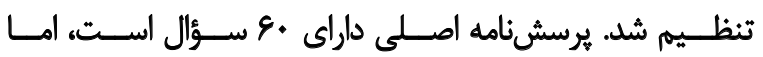

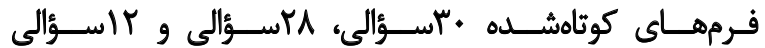

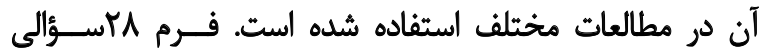

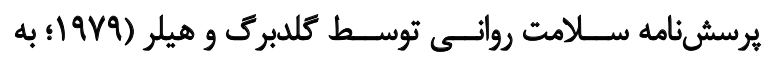

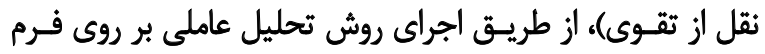

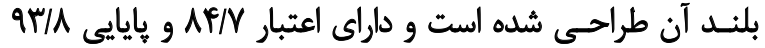

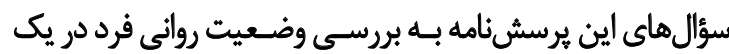

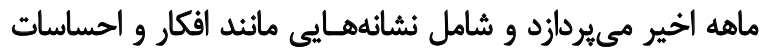

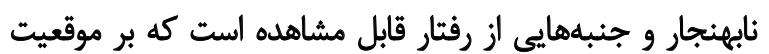

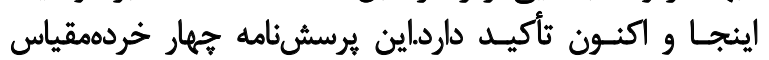

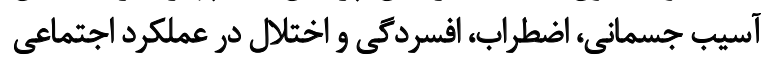

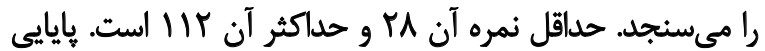

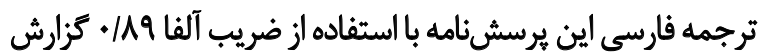

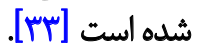
مثياس درجهابئدى اوتيسم, كودكى اين مقياس اولينبار در سال 1971 به منظور ارزيابى رفتارهاى

جدول r. خصوصيات جمعيتشناختى هايهاي در دو كروه

\begin{tabular}{|c|c|c|c|c|c|}
\hline \multirow{2}{*}{$\mathbf{P}$} & \multicolumn{2}{|l|}{ كروه كتثرل } & \multicolumn{2}{|l|}{ مروها آزمايش } & \multirow{2}{*}{ متغيرها } \\
\hline & ميانئين土|نحراف معيار & $\mathbf{N}$ & ميانغيندانحراف معيار & $\mathbf{N}$ & \\
\hline ./gar & $F / Y \wedge \pm r / M$ & 10 & $r / \Delta / \pm r / \circ \varepsilon$ & 10 & سن ثقويمى كودى \\
\hline - IEYA & & $r / N$ & & $r / M r$ & نسبت يسر به دختر \\
\hline - IEPT & & $e+1$ & & er/va & شدت اوتيّهم ير اساس CARS \\
\hline - NEA & & ro & & ra & هيانكين سنى هادر \\
\hline .1 .94 & & $\begin{array}{l}r \\
q \\
r\end{array}$ & & $\begin{array}{c}i \\
1 . \\
1\end{array}$ & - ذانشكاهي و بالاتر - زييلم - مسواد \\
\hline
\end{tabular}


جدول r. نتايج بهدستآمده از تحليل كوواريانس جندمتغيرى بر ميانكينهاى بـ آزمون مدل آموزش روانشناختى

\begin{tabular}{|c|c|c|c|c|c|c|}
\hline مقدار اثر & سطح معنى دارى & مقدار F & ميانكين مجذورات & DF & مراحل & متغير \\
\hline$+/ 9 \Delta+$ & $\% 1$ & $r g r / F A T$ & $r / \lambda r q$ & 1 & يس آزمهون & \multirow{2}{*}{ كاركرد خانواده } \\
\hline . MAP & $.1 .+1$ & $|9| 9 M \mid$. & T/q\&A & 1 & ييكيرى & \\
\hline.$/ 9 \pi r$ & $.1 . .1$ & TNEIII & T/MF & 1 & يسأزمون & \multirow{2}{*}{ راهبردهاى مقابلهاى } \\
\hline$\cdot / \Lambda \Delta \Delta$ & $.1 . .1$ & IEEMTE & INIV & 1 & ييكيرى & \\
\hline.$/ १ \Delta \Delta$ & $.1 . .1$ & PQNer. & $r / Q \Delta A$ & 1 & يس آزهون & \multirow{2}{*}{ سلامت روان } \\
\hline.$/ 9 \cdot 1$ & $.1 .+1$ & IW/N.r & $T / M$. & 1 & يبيكيرى & \\
\hline . /apr & $.1 . .1$ & mIV/aq. & $r \cdot / \Delta r A$ & 1 & يسأزمون & \multirow{2}{*}{ طشانكان بالينى اختلال } \\
\hline ./APA & $1 .+1$ & rDNY $+\varphi$ & $1 \% / / 99 \Delta$ & 1 & ييكيرى & \\
\hline
\end{tabular}

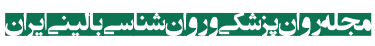

جدول F. نتايج آزمون تعقيبى بونفرونى درباره اثرات مداخله آموزش روانشئاختى بر مؤلفههاى مورد سنجش

\begin{tabular}{|c|c|c|c|c|c|c|}
\hline سطح معنى دارى & خطاى استاندارد & |ختلاف (J-I) & كروه ل & كروها & \multicolumn{2}{|c|}{ متغير وابسته } \\
\hline $.1 .+1$ & سז &.$- /$ Ter & كتنرل & آزمايش & بس آزمون & \multirow{2}{*}{ كاركرد خانواده } \\
\hline $.1++1$ & .1 .49 & $-2 / / 4+8$ & كتترل & أزمايش & ييكيرى & \\
\hline $.1 .+1$ &.$/ \% \mathrm{rr}$ & אזr/.- & كتترل & أزمايش & يس آزمون & \multirow{2}{*}{ راهبردهاى مقابلهاى } \\
\hline.$/ .1$ & $\%$. Fa & - & كتترل & أزمايش & ييكيرى & \\
\hline .1 .01 & g & - & كتترل & أزمايش & يسآزمون & \multirow{2}{*}{ سلامت روان } \\
\hline $.1 . .1$ & $\%$ &.$-|\Delta|$ & كتثرل & أزمايش & ييكيرى & \\
\hline
\end{tabular}

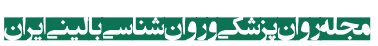

$$
\text { بيشترى نسبت به كروه كنترل نشان دادند. }
$$

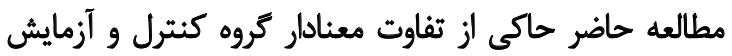

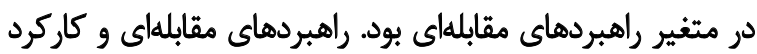

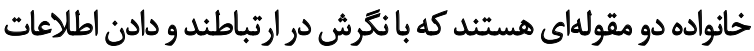

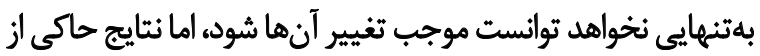

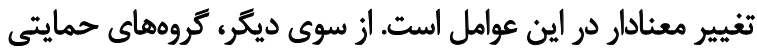

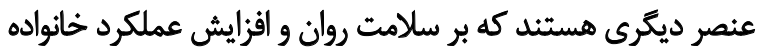

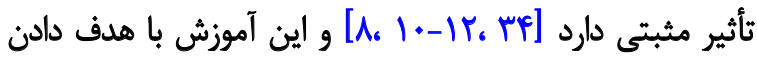

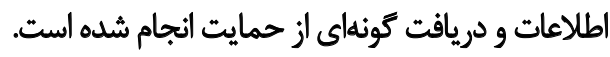
يُروهش هاى بسيارى نشاندهنده تأثير مثبت آموزش والدين و

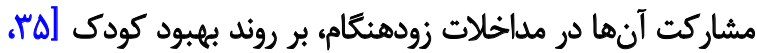

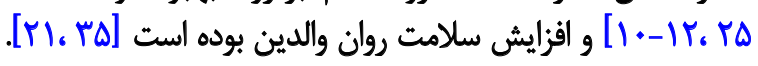

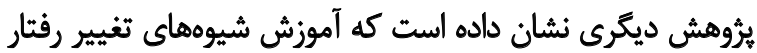

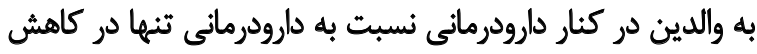

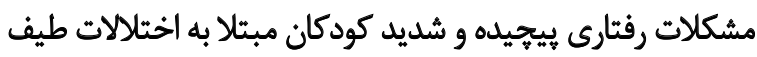

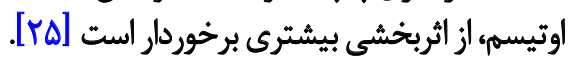
شواهدى وجود دارد كه آموزش والدين اثربخشى درمانهاي

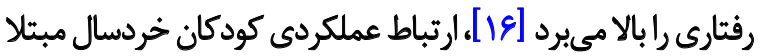

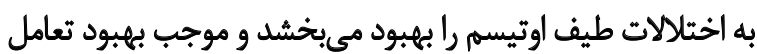

تحليل كوواريانس جندمتغيرى بيانكر اثربخشى معنى دار آموزش

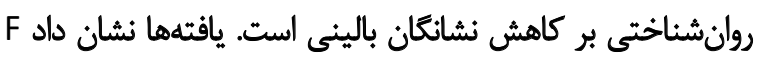

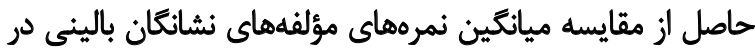

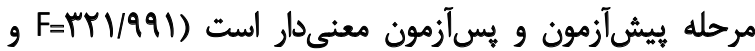

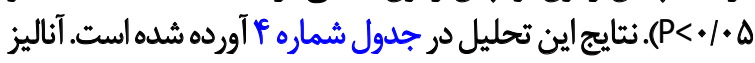

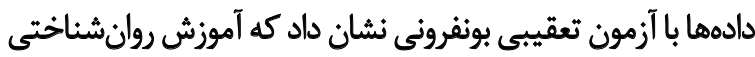

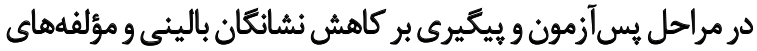

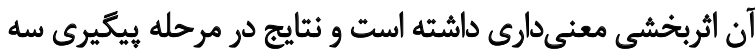

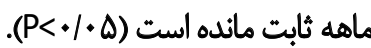

\section{بحث}

بر اساس مطالعات، برنامههاي آموزش والدين مى تواند منجر به

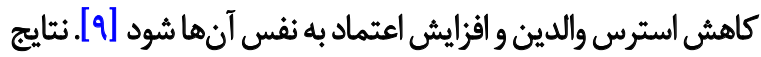

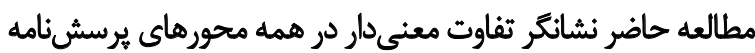

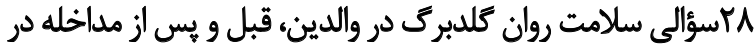

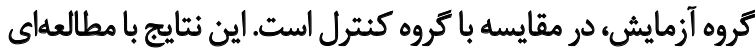

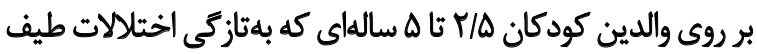

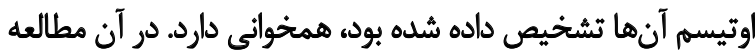

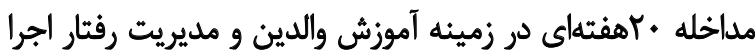

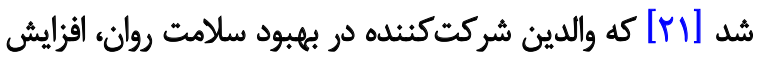


آنها و خائوادهشان نيز خواهند داشت. از جمله محدوديتهاى اين مطالعه ميتوان به كزئ بزينش نمونه

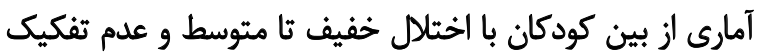

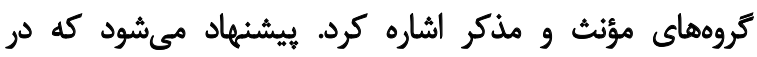

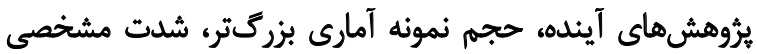

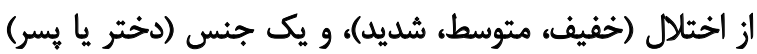

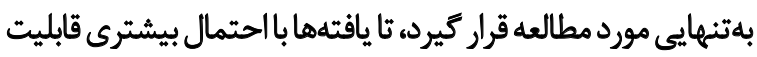

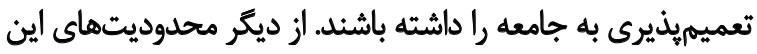

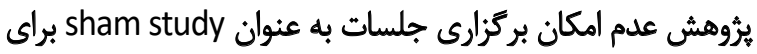

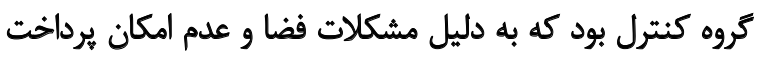
هزينههاى اياب و ذهاب براى والدين انجام نشد.

مالاحظاث اخلاقى تري

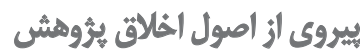

همه اصول اخلاقي در اين مقاله رعايت شده است. شركت

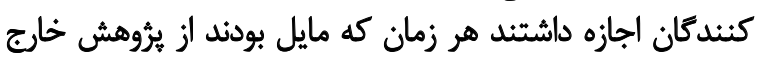

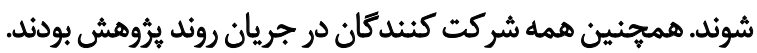
اطلاعات آن ها محرمانه نكَه داشته شد كند

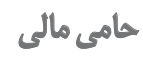

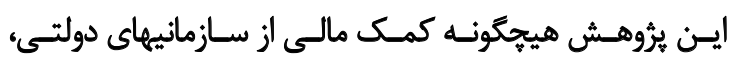

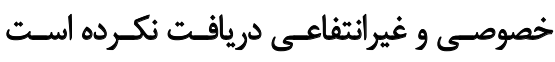

$$
\text { مشاركت ثويسندكان }
$$

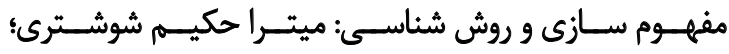

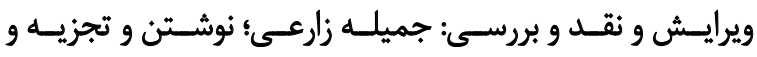

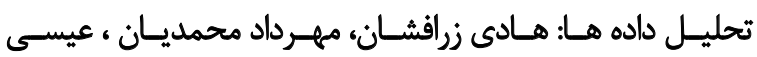

كريمسى كيسـومي ، هوشــنكي هليـا.

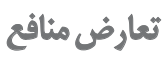

بنابر اظهار نويسندكان، اين مقاله تعارض منافع ندارد.
والد - كودى مي شود [1A]. درتحقيق ديكرى كه توسط تاكاشى و

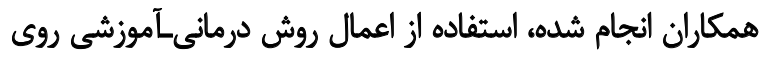

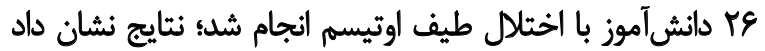

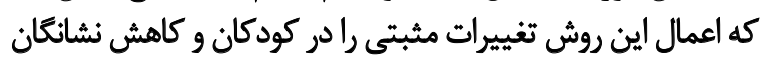

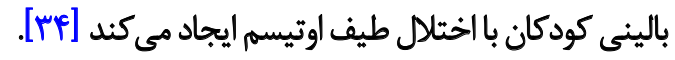

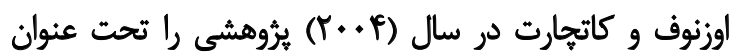

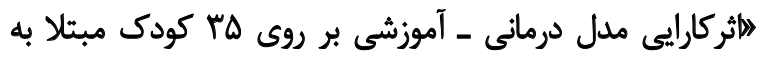

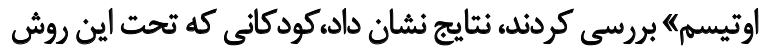

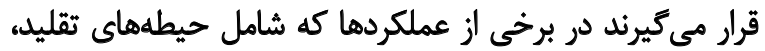

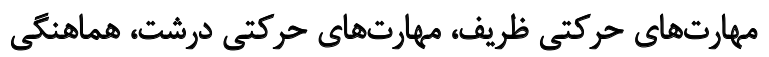

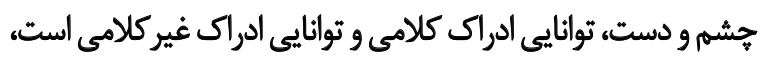

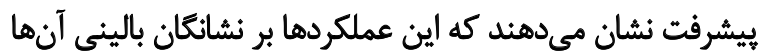

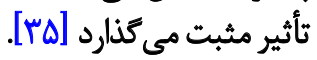

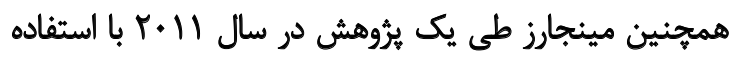

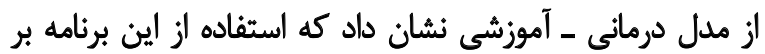

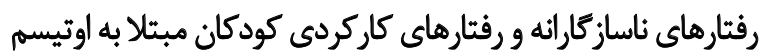

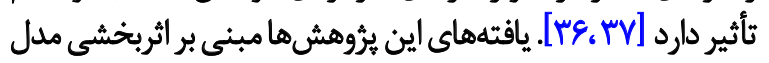

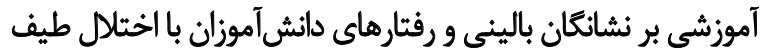

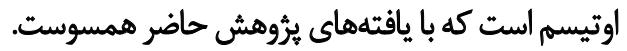

يُروهش هاى انجامشده در ايران نشان مى دهد والدين ايرانى مانئد

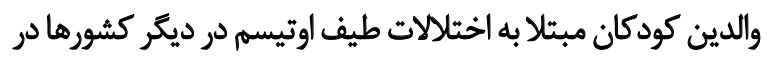

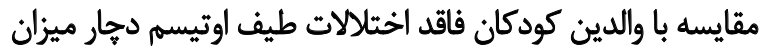

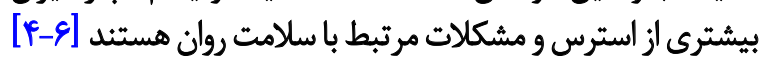

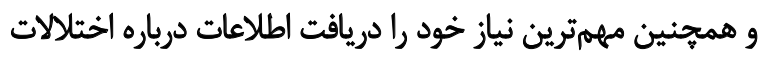

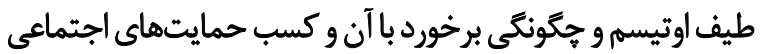

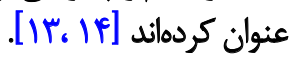
اجراي اين برنامه نشان داد كه داشتن اطلاعاتى در مورد بيمارى

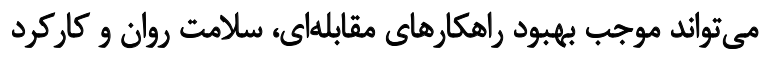

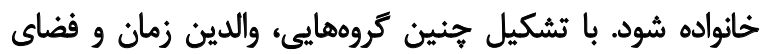

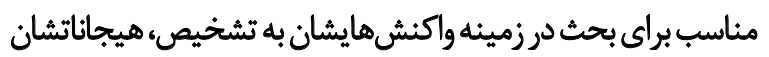

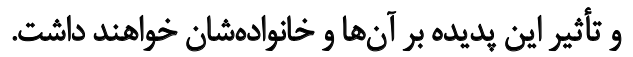

\section{نتيجِكَّيرى}

مطالعه حاضر اهميت آموزش گروهى والدين در زمينه اختلالات

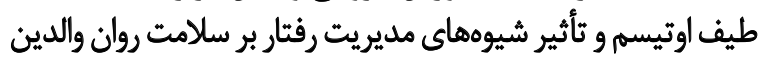

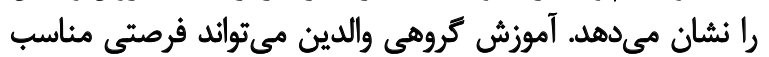

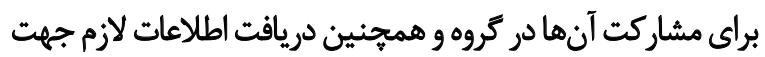

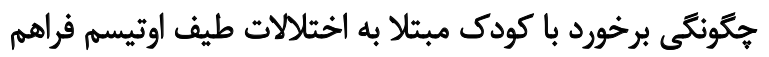

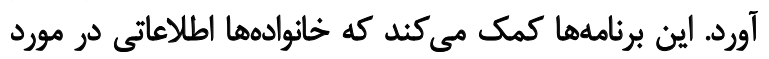

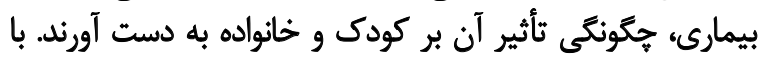

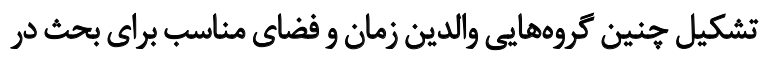
زمينه واكنش جايشان به تشخيص، هيجاناتشان و تأثير اين بديديد بران بحثر 


\section{References}

[1] Hillman J. Grandparents of children with autism: A review with recommendations for education, practice and policy. Educational Gerontology. 2007; 33(6):513-27. [DOI:10.1080/03601270701328425]

[2] Little L. Differences in stress and coping for mothers and fathers of children with Asperger's syndrome and nonverbal learning disorders. Pediatric Nursing. 2002; 28(6):565-70.[PMID]

[3] Solomon M, Goodlin-Jones BL, Anders TF. A social adjustment enhancement intervention for high functioning autism, Asperger's syndrome, and pervasive developmental disorders NOS. Journal of Autism and Developmental Disorders. 2004; 34:649-68 [DOI:10.1007/s10803-004-5286-y] [PMID]

[4] Khoramabadi R, Pouretemad HR, Tahmasian K, Chimeh N. [A comparative study of parental stress in mothers of autistic and non-autistic children (Persian)]. Journal of Family Research. 2009; 5(3):387-99.

[5] Afshari R, Khushabi K, Poretemad HR, Moradi Sh. [Coping strategies and mental health in autistic children mothers (Persian)]. Journal of Family Research. 2006; 2(3):285-92

[6] Khushabi K, Farzad Fard SZ, Kakasoltani B, Pouretemad HR, Nikkhah HR. [Coping strategies and stress in mothers with autistic children in comparison with mothers with normal children (Persian)]. Journal of Family Research. 2010; 6(1):87-97.

[7] White N, Hastings RP. Social and professional support for parents of adolescents with severe intellectual disabilities. Journal of Applied Research in Intellectual Disabilities. 2004; 17(3):181-90. [DOI:10.1111/j.1468-3148.2004.00197.x]

[8] Freedman RI, Boyer NC. The power to choose: Supports for families caring for individuals with developmental disabilities. Health \& Social Work. 2000; 25(1):59-68. [DOI:10.1093/hsw/25.1.59] [PMID]

[9] Sanders JL, Morgan SB. Family stress and adjustment as perceived by parents of children with autism or Down syndrome: Implications for intervention. Child \& Family Behavior Therapy. 1997; 19(4):15-32. [DOI:10.1300/J019v19n04_02]

[10] Siklos S, Kerns KA. Assessing need for social support in parents of children with autism and Down syndrome. Journal of Autism and Developmental Disorders. 2006; 36:921-33. [DOI:10.1007/ s10803-006-0129-7] [PMID]

[11] Smith K, Gabard D, Dale D, Drucker A. Parental opinions about attending parent support groups. Children's Health Care. 1994; 23(2):127-36. [DOI:10.1207/s15326888chc2302_5] [PMID]

[12] Tellen S, Herzog A, Kilbane TL. Impact of a family support program on mothers' social support and parenting stress. American Journal of Orthopsychiatry. 1989; 59(3):410-9. [DOI:10.1111/j.1939-0025.1989.tb01676.x] [PMID]

[13] Ahmadi A, Sharifi E, Azizi Zalani H, Bolouk Sh, Amrai K. The needs of Iranian families of children with autism spectrum disorder, cross-cultural study. Procedia - Social and Behavioral Sciences. 2011; 15:321-6. [DOI:10.1016/j.sbspro.2011.03.094]

[14] Samadi SA, Mahmoodizadeh A, McConkey R. A national study of the prevalence of autism among five-year-old children in Iran. Autism. 2012; 16(1):5-14. [DOI:10.1177/1362361311407091] [PMID]
[15] Ivar Lovaas O, Koegel R, Simmons JQ, Long JS. Some generalization and follow-up measure on autistic children in behavior therapy. Journal of Applied Behavior Analysis. 1973; 6(1):131-65. [DOI:10.1901/jaba.1973.6-131] [PMID] [PMCID]

[16] Schreibman L. Intensive behavioral/psychoeducational treatment for autism: Research needs and future directions. Journal of Autism and Developmental Disorders. 2000; 30:373-8. [DOI:10.1023/A:1005535120023] [PMID]

[17] Schreibman L, Anderson A. Focus on integration: The future of the behavioral treatment of autism. Behavior Therapy. 2001 32(4):619-32. [DOI:10.1016/S0005-7894(01)80012-5]

[18] Moes D, Frea W. Contextualized behavioral support in early intervention for children with autism and their families. Journal of Autism and Developmental Disorders. 2002; 35:519-33. [DOI:10.1023/A:1021298729297] [PMID]

[19] Koegel R, Bimbela A, Schreibman L. Collateral effects of parent training on family interactions. Journal of Autism and Developmental Disorders. 1996; 26:347-59. [DOI:10.1007/BF02172479] [PMID]

[20] Vismara LA, Colombi C, Rogers S. Can one hour a week of therapy lead to lasting changes in young children with autism? Autism. 2009; 13(1):93-115. [DOI:10.1177/1362361307098516] [PMID] [PMCID]

[21] Tonge B, Brereton A, Kiomal M, Mackinnon A, King N, Rinehart N. Effects on parental mental health of an education and skills training program for parents of young children with autism: A randomized control trial. Journal of the American Academy of Child \& Adolescent Psychiatry. 2006; 45(5):561-9. [DOI:10.1097/01.chi.0000205701.48324.26] [PMID]

[22] Sofronoff K, Leslie A, Brown W. Parent management training and Asperger syndrome: A randomized controlled trial to evaluate a parent based intervention. Autism. 2004; 8(3):301-17. [DOI:10.1177/1362361304045215] [PMID]

[23] Rickards AL, Walstab JE, Wright-Rossi RA, Simpson J, Reddihough DS. A randomized, controlled trial of a home-based intervention program for children with autism and developmental delay. Journal of Developmental \& Behavioral Pediatrics. 2007; 28(4):308-16. [DOI:10.1097/DBP.0b013e318032792e] [PMID]

[24] Glidden LM, Jobe BM. Measuring parental daily rewards and worries in the transition to adulthood. American Journal of Mental Retardation. 2007; 112(4):275-88. [DOI:10.1352/08958017(2007)112[275:MPDRAW]2.0.CO;2] [PMID]

[25] Aman MG, Mcdougle CJ, Scahill L, Handen B, Arnold E, Johnson C. et al. Medication and parent training in children with pervasive developmental disorders and serious behavior problems: Results from a randomized clinical trial. Journal of the American Academy of Child and Adolescent Psychiatry. 2009; 48(12):114354. [DOI:10.1097/CHI.0b013e3181bfd669] [PMID] [PMCID]

[26] Billings AG, Moos RH. The role of coping responses and social; resources in attenuating the stress of life events. Journal of Behavioral Medicine. 1981; 4:139-57. [DOI:10.1007/BF00844267] [PMID]

[27] Goldberg DP, Hillier VF. A scaled version of the General Health Questionnaire. Psychological Medicine. 1979; 9(1):139-45. [DOI:10.1017/S0033291700021644] [PMID]

[28] Schopler E, Reichler RJ, Renner BR. The Childhood Autism Rating Scale (CARS): For diagnostic screening and classification of autism. New York: Irvington; 1986. 
[29] Schopler E, Reichler RJ, Lansing MD. Individualized Assessment and Treatment for Autistic and Developmentally Disabled Children. Baltimore: University Park Press; 1980.

[30] Epstein NB, Baldwin LM, Bishop DS. The McMaster family assessment device. Journal of Marital and Family Therapy. 1983; 9(2):171-80.[DOI:10.1111/j.1752-0606.1983.tb01497.x]

[31] Zadeh Mohammadi A, Malek Khosravi Gh. [The preliminary study of psychometric and reliability of family assessment device (Persian)]. Journal of Family Research. 2006; 2(5):69-89.

[32] Zenoozian S, Gharaee B, Yekke Yazdandoost R. [Efficacy of problem solving training in changing coping strategies of university students (Persian)]. Journal of Psychology (Tabriz University). 2011; 5(20):83-101.

[33] Williams JG, Higgins JPT, Brayne CEG. Systematic review of prevalence studies of autism spectrum disorders. Archives of Disease in Childhood. 2006; 91(1):8-15. [DOI:10.1136/ adc.2004.062083] [PMID] [PMCID]

[34] Ichikawa K, Takahashi $\mathrm{Y}$, Ando M, Anme T, Ishizaki T, Yamaguchi $\mathrm{H}$, et al. TEACCH-based group social skills training for children with high-functioning autism: A pilot randomized controlled trial. BioPsychoSocial Medicine. 2013; 7:14. [DOI:10.1186/1751-0759-7-14] [PMID] [PMCID]

[35] Ozonoff S, Pennington BF, Rogers SJ. Executive function deficits in high-functioning autistic individuals: Relationship to theory of mind. Journal of Child Psychology and Psychiatry. 1991; 32(7):1081-105. [DOI:10.1111/j.1469-7610.1991.tb00351.x] [PMID]

[36] Minjarez MB, Williams EM, Mercier EM, Hardan AY. Pivotal response group treatment program for parents of children with autism. Journal of Autism and Developmental Disorders. 2011; 41:92-101. [DOI:10.1007/s10803-010-1027-6] [PMID]

[37] Mohseni Ejiyeh AR, Abedi A, Behnamnejad N. [Effectiveness of Applied Behavior Analysis (ABA) for children with autism spectrum disorders in Iran, 2005-2013: A meta-analysis (Persian)]. Iranian Journal of Psychiatry \& Clinical Psychology. 2015; 21(1):17-25. 